\title{
The relationship between breast-feeding and infant health and development
}

\author{
BY J. S. FORSYTH \\ Department of Child Health, Ninewells Hospital and Medical School, Dundee DD1 9SY
}

\begin{abstract}
Advocacy for the practice of breast-feeding is not a recent phenomenon. Reference to the importance of breast-feeding is recorded in several historical and religious texts including the Koran and the writings of Hippocrates. However, despite these, and many other more recent influential epistles, we approach the end of the second millennium with the majority of infants in the UK being artificially fed. The reason why parents are not receptive to widely publicised advice on the benefits of breast-feeding is unclear but one can presume that they are not convinced by the evidence in favour of breast-feeding and do not perceive artificial feeding as being less than optimum for their child. For parents to make an objective choice of type of infant feeding they must be provided with information which is at least substantive and preferably unequivocal. The benefits of breast-feeding which are most frequently stated in the literature are that human milk protects against infection and allergic disease and will also enhance the child's intellectual potential. These are impressive claims and if thoroughly proven would surely influence the most sceptical parents in favour of breast-feeding. The purpose of the present paper, therefore, is to examine the validity of these claims in more detail with special emphasis being placed on the clinical evidence.
\end{abstract}

\section{DOES BREAST-FEEDING PROTECT THE INFANT AGAINST INFECTION?}

\section{Laboratory evidence}

About 100 years ago, Ehrlich (1892) demonstrated that milk contains protective factors and although it was realized that some of these factors would be antibodies, it was not until 1961 (Hanson, 1961) that the main human-milk immunoglobulin secretory immunoglobulin A (SIgA) was characterized immunologically and isolated. SIgA concentrations fall during lactation from approximately $2 \mathrm{~g} / \mathrm{l}$ at week 1 to approximately $0.8 \mathrm{~g} / \mathrm{l}$ at week 12 (McClelland et al. 1978). Despite these decreases in concentrations the intakes of the immunoproteins are substantial whenever milk provides a significant proportion of the total diet. The inter-individual variability in their concentration is large, varying by approximately $20-30 \%$ or more. The SIgA antibodies are against a wide range of bacterial, viral, parasitic, fungal and food antigens. Various investigators have demonstrated that the specificity of human-milk SIgA depends on the mother's antigenic exposure (Hanson et al. 1979). The mechanism responsible for the appearance of these antibodies is only part ally understood (Hanson \& Brandtzaeg, 1988). Sensitized plasma cells are transported from the gastrointestinal and bronchotracheal-associated lymphatic tissues to multiple mucosal surfaces including breast alveoli during lactation. During lactation the homing of these cells to the breast appears to be activated by lactoge ic hormones. The $a b{ }^{\prime}$ of the mother to secrete antibodies directed against specific $n$ igens that she and e nfant encounter in the environment would appear to g ve huma milk an environm $n \quad I$ specificity and significant protective potential.

Lac of $r$ in is a milk specifi $F$ binding glycoprotein and it plays an essential role in 
Fe absorption in the intestine. Lactoferrin avidly binds free $\mathrm{Fe}$ in human milk and, therefore, is thought to limit $\mathrm{Fe}$ availability to potentially pathogenic enteric flora by competing with bacterial demands for $\mathrm{Fe}$. Concentrations of lactoferrin fall from approximately $5 \mathrm{~g} / 1$ at week 1 of lactation to $1 \mathrm{~g} / \mathrm{l}$ at week 12 and remain relatively stable thereafter (Reddy et al. 1977).

Lysozyme ( $E C$ 3.2.1.17), another non-specific protective factor catalyses the hydrolysis of specific molecular bonds in bacterial cell walls. The pattern of lysozyme secretion differs from that of lactoferrin in that the levels increase during lactation (Reddy et al. 1977).

These non-specific protective proteins may act synergistically with each other and with SIgA to enhance specific functional effect, e.g. the anti-Escherichia coli effects of lactoferrin and SIgA acting in concert are greater than those of either component acting alone (Stephens et al. 1984). SIgA also interacts with cellular elements of the immune system. More recently, the multipurpose roles of some of the human milk constituents have become more apparent in that the enzyme, bile salt-stimulated lipase ( $E C$ 3.1.1.3), recognized for being an active component in fat digestion in the newborn infant, has more recently been shown to be one of the active agents in the killing of the common intestinal parasite Giardia lamblia (Hernell \& Blackberg, 1988). Although viable white cells have been identified in human milk their role is not clear, their contribution may be negligible as they might not survive the high acidity of the gastric secretions.

In conclusion, there is extensive laboratory data which gives weight to the hypothesis that breast milk protects the infant from infection, but is this supported by the clinical evidence?

\section{Clinical evidence}

There is considerable published evidence from developing countries that breast-feeding does protect infants from gastrointestinal infection. However, there has been much less agreement about similar effects of breast-feeding in developed countries. Bauchner et al. (1986) reviewed all studies published on this subject since 1970 which were written in the English language. Four important methodological criteria that they applied to these reports were: avoidance of detection bias, adjustment for potential confounding variables, definition of outcome events and definition of infant feeding. They concluded that of the fourteen cohort and six case-control studies only two met all four criteria, four met three criteria, and the two that met all four criteria had small numbers. The overall conclusion was that most studies had major methodological flaws and that breast-feeding had at most a minimal protective effect in industrialized societies.

In Dundee, we (Howie et al. 1990) undertook a study of the effect of breast-feeding on childhood illness which met all the methodological criteria described by Bauchner et al. (1986). Our results showed that after adjustments were made for confounding variables, infants who were breast-fed for 13 weeks or more had significantly less gastrointestinal illness than those who were bottle-fed from birth at ages $0-13$ weeks $(P<0 \cdot 01), 14-26$ weeks $(P<0 \cdot 01), 27-39$ weeks $(P<0 \cdot 05)$ and $40-52$ weeks $(P<0.05$; Fig. 1$)$. This reduction in illness was found whether or not supplements were introduced before 13 weeks, was maintained beyond the period of breast-feeding itself and was accompanied by a reduction in the rate of hospital admission. By contrast, infants who were breast-fed for less than 13 weeks, had rates of gastrointestinal illness similar to those observed in 

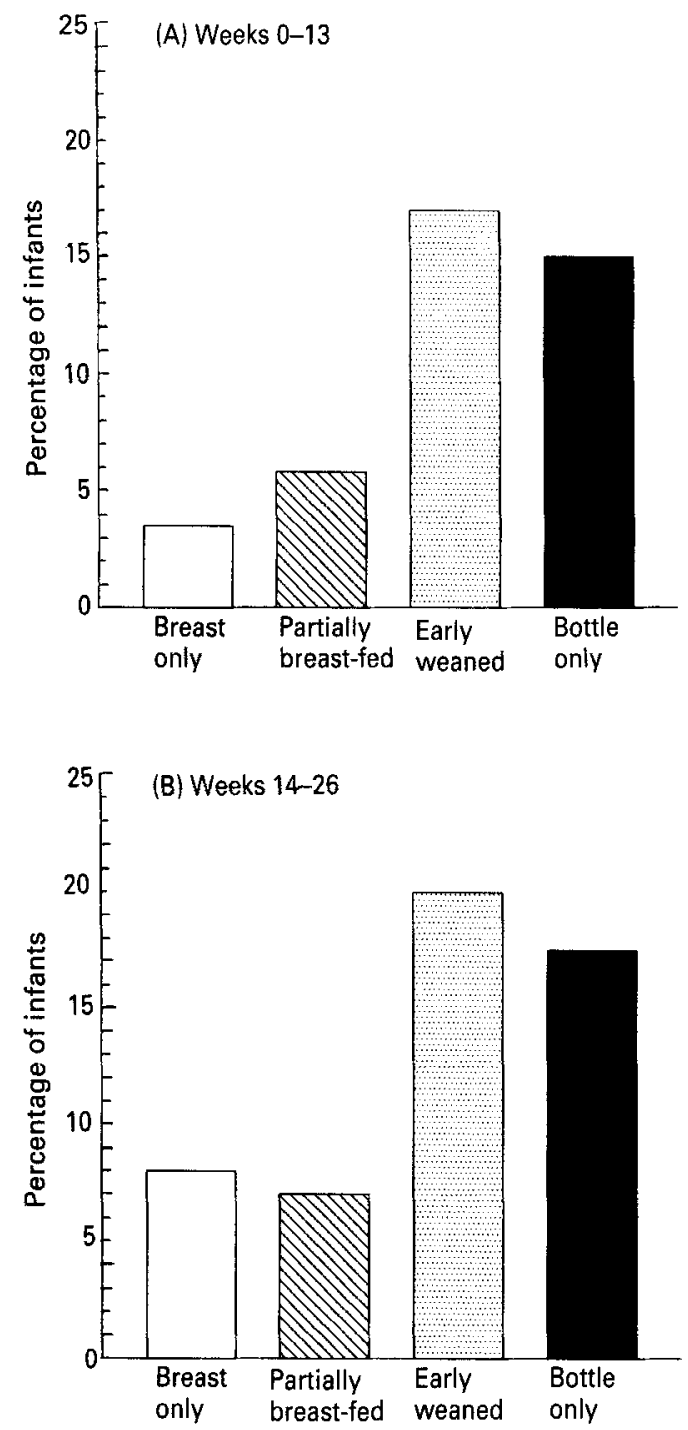

Fig. 1. Relationship between gastrointestinal illness and the type of milk fed from 0 to 52 weeks of age, adjusted for social class, maternal age and parental smoking. Values for breast-fed infants were significantly different from those for early-weaned and bottle-fed infants: at weeks $0-13$ and weeks $14-36 P<0 \cdot 01$, at weeks $27-39$ and $40-52 P<0 \cdot 05$. (Continued on next page.)

bottle-fed infants. Smaller reductions in the rates of respiratory illness were observed at ages of $0-13$ weeks and 40-52 weeks $(P<0.05)$ in infants who were breast-fed for more than 13 weeks. There was no consistent protective effect against ear, eye, mouth or skin infection.

We concluded from our findings that breast-feeding during the first 13 weeks of life confers protection against gastrointestinal illness that persists beyond the period of breast-feeding itself. These findings are in keeping with a recent global epidemiological 
Continued from previous page
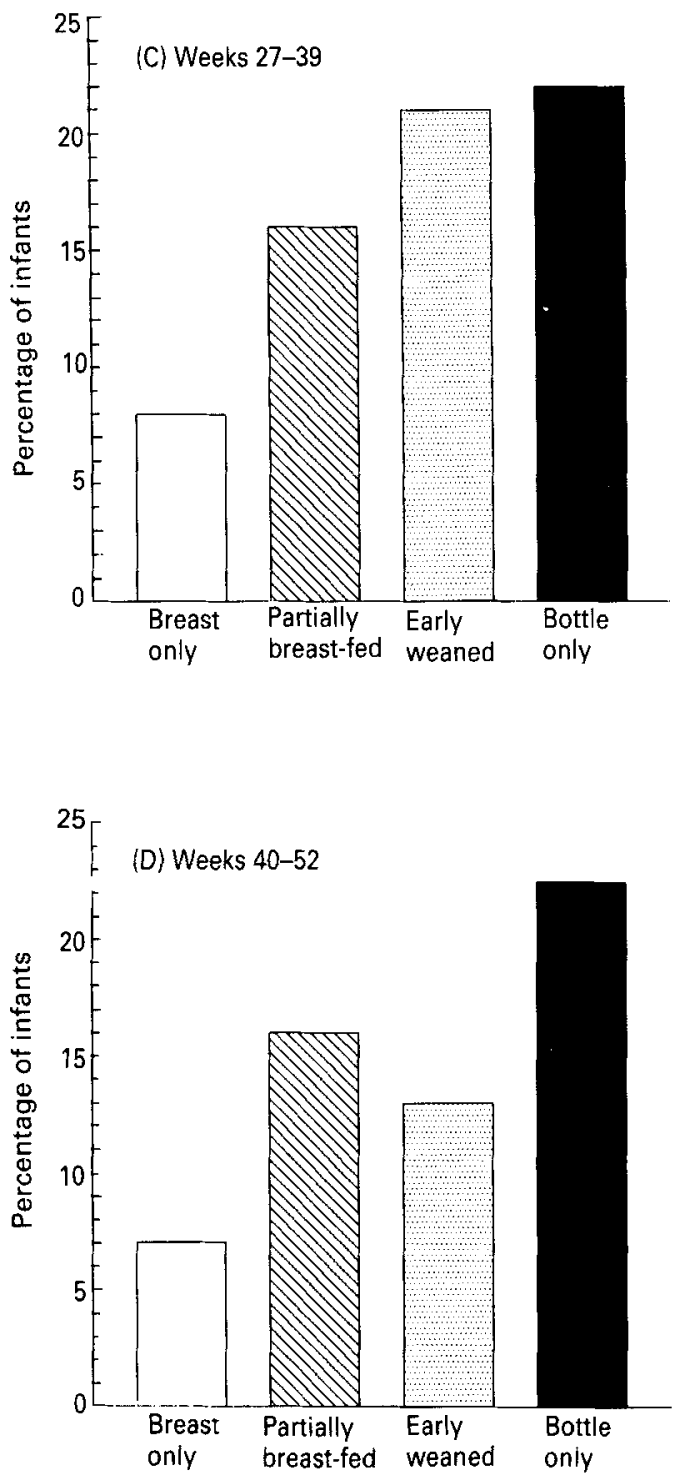

review which concluded that breast-feeding reduced illness in early life (Cunningham et al. 1991).

The mechanism whereby breast-feeding continues to provide a protective effect after the discontinuation of feeding is uncertain, but there is recent evidence suggesting that human milk may have properties which stimulate the maturation of the immune system of the recipient. In a prospective study of infants' response to respiratory syncytial virus infection, not only was the severity of illness less in breast-fed infants but the serum levels of interferon-alpha were substantially higher in the breast-fed infants and the 
difference could not be explained by the small amounts of interferon-alpha which are present in breast milk (Chiba et al. 1987). In a second study, serum levels of fibronectin, a broad spectrum opsonin, were found to be significantly higher in breast-fed infants (Friss et al. 1988). Laboratory studies have shown that there are factors in human milk which have a stimulating effect on the proliferation of and immunoglobulin synthesis by lipopolysaccharide-primed splenic murine B cells. It has been suggested that these factors may be cytokines such as tumour necrosis factor- $\alpha$ (Goldman et al. 1991).

\section{DOES BREAST-FEEDING PREVENT THE DEVELOPMENT OF}

\section{ALLERGIC DISEASE?}

On the premise that artificially-fed infants are ingesting nutrients derived from a different species and, thus, foreign to the newborn infant, there has been considerable interest in the potential relationship of breast-feeding and protection from the development of allergic disease.

In the normal adult, antigens which traverse the mucosal epithelium induce a local immune response resulting in the production of dimeric IgA by primed IgA-producing plasma cells in the lamina propria. The specific $\operatorname{IgA}$ is then bound to the secretory component, an epithelial glycoprotein receptor, and transported across the epithelium to be released onto the mucosal surface. It is postulated that this specific IgA binds antigen in the intraluminal environment, thus suppressing the transport of further antigen across the epithelium (Walker \& Isselbacher, 1977). Although the secretory component of the $\operatorname{IgA}$ complex is normally present in the intestinal mucosa by 22 weeks gestation, IgA-producing cells are not seen in the mucosa of the intestine until approximately $12 \mathrm{~d}$ of age. Susceptibility to immunoreactive antigens depends on many factors including availability of SIgA, mucosal barrier permeability and degree of fragmentation of antigens during the digestive process. In contrast to artificial milk, human milk contains a number of factors including hormones, peptides, amino acids and glycoproteins which may act to promote gastrointestinal maturation (Koldovsky et al. 1988).

It is almost 60 years since Grulee \& Sanford (1936) first reported that breast-feeding protected infants against eczema. Since then there have been many studies attempting to confirm these findings and also to determine if there is protection against other allergic disorders such as rhinitis and asthma. A review by Kramer (1988) highlighted the current divergence of views which was thought to be explained in part by variation in study groups and other methodological factors (Table 1). A protective effect has most consistently been reported in infants with a genetic propensity for allergic disease. There is evidence that sensitization may occur in breast-fed infants who have not been exposed to foreign food proteins suggesting that sensitization to food antigens via breast milk is possible in atopic individuals. Intra-uterine sensitization is rare. This is surprising because the fetus produces immunoglobulin $\mathrm{E}$ (IgE) from the 11th week of gestation (Miller et al. 1973). Two studies have clearly shown that even large variations in maternal intake of egg and cow's milk during the last trimester of pregnancy did not influence cord-blood IgE levels, the presence of specific IgE levels against foods nor the incidence of allergic disease at 18 months (Duchen \& Bjorksten, 1991). More recently the relationship between early solid feeding and allergic disease has attracted interest; Fergusson et al. (1981) provided evidence that the development of eczema may be related to the early introduction of solids and Forsyth et al. (1993) reported that there was increased 
Table 1. Breast-feeding and allergic disease (Modified from Kramer, 1988)

\begin{tabular}{lccr} 
& & \multicolumn{2}{c}{ Protection } \\
\cline { 3 - 4 } \cline { 3 - 4 } Allergic disorder & No. of & Yes & No \\
\hline Asthma & 13 & 7 & 6 \\
Eczema & 22 & 8 & 14 \\
Rhinitis & 7 & 2 & 5 \\
Mixed & 8 & 5 & 3 \\
\hline
\end{tabular}

respiratory illness during the first 2 years of life in infants receiving early solids, this association persisting after adjustment for type of milk feed.

\section{DOES BREAST-FEEDING BESTOW SPECIFIC ADVANTAGE TO THE INFANT IN INTELLECTUAL DEVELOPMENT?}

Several investigators have indicated that breast-fed infants may be advantaged in their subsequent development and intelligence quotient (IQ) compared with formula-fed infants (Hoefer \& Hardy, 1929; Taylor, 1977; Rodgers, 1978). The advantage has persisted after adjustments have been made for social, demographic and educational status, factors which are known to be related to developmental scores. Various constituents of human milk such as hormones, growth-promoting factors and specific nutrients including fatty acids, have been postulated as potential factors which may positively influence neural development. On the other hand, it has been suggested that the advantage to the infant is not due to the consumption of breast milk itself but related to the mother's decision to provide milk. A mother sufficiently concerned about her child's welfare to choose breast-feeding, may have a greater desire to stimulate and facilitate her baby's developmental progress (Pollock, 1989).

This issue was recently addressed by Lucas et al. (1992) who showed that preterm infants who received their mothers' milk had a substantial advantage in subsequent intelligence quotient (IQ) at age 7.5-8 years compared with those who did not receive mother's milk (Table 2 ). This difference persisted after adjustment was made for a wide range of factors which might have confounded this comparison. The study also reported a significant dose-response relationship between the proportion of mother's milk consumed and later development, and as the infants received their mothers' milk by

Table 2. Factors relating to intelligence quotient (IQ) at 7.5-8 years

(Modified from Lucas et al. 1992)

\begin{tabular}{lccc}
\hline \hline Factor & $\begin{array}{c}\text { Increase } \\
\text { in IQ }\end{array}$ & $\begin{array}{c}\text { Statistical } \\
\text { confidence } \\
\text { intervals }\end{array}$ & $\begin{array}{c}\text { significance of } \\
\text { increase: } P\end{array}$ \\
\hline Received mother's milk & $8 \cdot 3$ & $4 \cdot 9,11 \cdot 7$ & $<0 \cdot 0001$ \\
Social class (/class) & $-3 \cdot 5$ & $-1 \cdot 5,-5 \cdot 5$ & $0 \cdot 0004$ \\
Mother's education (/group) & $2 \cdot 0$ & $0 \cdot 5,3 \cdot 5$ & $0 \cdot 01$ \\
Female sex & $4 \cdot 2$ & $1 \cdot 0,7 \cdot 4$ & $0 \cdot 01$ \\
Period of ventilation (d/week) & $-2 \cdot 6$ & $-3 \cdot 7,-1 \cdot 5$ & $0 \cdot 02$ \\
\hline
\end{tabular}



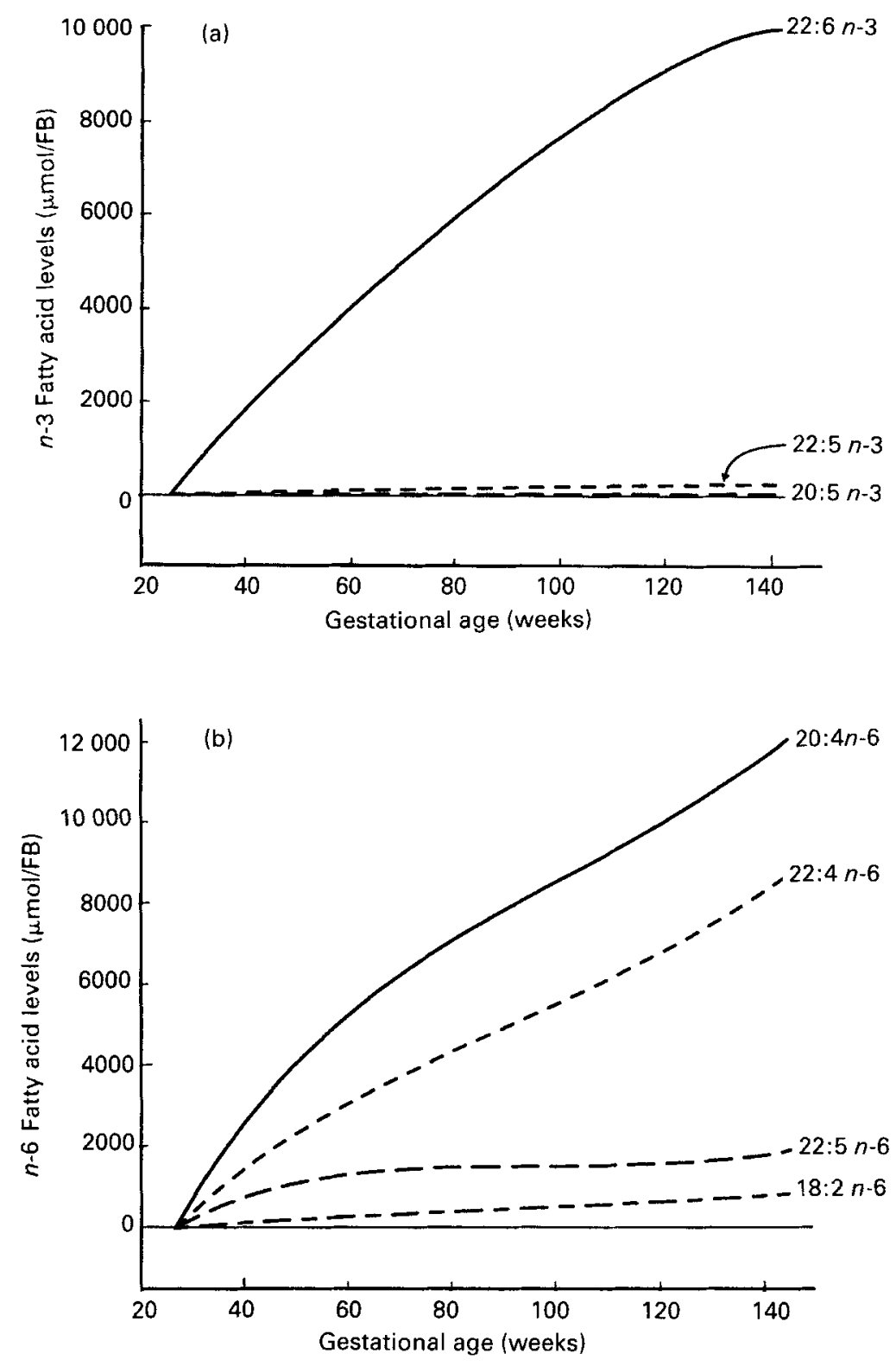

Fig. 2. Levels of (a) $n-3$ and (b) $n-6$ fatty acids in the forebrains (FB) of thirty-four infants including both preterm and postnatal normally-fed infants up to 2 years of age (Modified from Martinez, 1992).

nasogastric tube, it was concluded that the observed advantage could not be due to interaction between mother and child during the process of suckling. Correspondence following this publication raised the question of whether adjustment for potentially confounding variables such as maternal education attainment and social class adequately eliminated the parental factors (Wright \& Deary, 1992). It has been suggested that these 
factors are only moderately good surrogates for maternal $\mathrm{IQ}$, and $70 \%$ of IQ is related to hereditability factors (Bouchard et al. 1990).

Although there are limitations in all the studies hitherto supporting the view that breast milk does confer some intellectual advantage to the infant, there is sufficient weight of evidence to encourage investigation of those factors in the milk which may initiate this benefit. Currently, the most favoured explanation involves the role of long-chain polyunsaturated fatty acids (LCP). Of the structural material of the brain $60 \%$ is lipid, and an important functional component of this lipid are LCP (Crawford \& Sinclair, 1972; Martinez, 1992; Fig. 2). These LCP are derived from the essential $C_{18}$ fatty acids, $n-6$ linoleic acid and $n-3 \alpha$-linolenic acid through elongase and desaturase enzyme systems. It was assumed that the term and preterm infant would be able to synthesize the longer-chain fatty acids but there is increasing evidence that, during the first few months of life, preterm infants and young term infants may not be able to elongate or desaturate the parent LCP linoleic acid and $\alpha$-linolenic acid to their functional derivatives arachidonic acid (AA) and docosahexaenoic acid (DHA) respectively (Clark et al. 1992). As a result, there may be a deficiency of LCP at a critical time of brain growth and development.

Carlson et al. $(1985,1987)$ have demonstrated that preterm infants reared on mother's milk had near normal levels of DHA, whereas those fed on standard milk formula or standard formula to which $\alpha$-linolenic acid was added, continued to show low DHA levels. Only when the formula was supplemented with fish oii containing DHA did the preterm infant DHA level reach that found in those fed on their mother's milk (Carlson et al. 1985, 1987). Similar differences have been demonstrated also in term infants, supporting the view that formulas containing only linoleic acid and $\alpha$-linolenic acid may not be effective in meeting the full essential fatty acid requirements of healthy term infants (Clark et al. 1992). The studies on blood lipids are relevant because it has been shown that the fatty acid composition of the erythrocyte membrane reflects that of neural tissue. In support of this, recent reports on the brain lipid composition of infants fed on human milk or formula milk have shown a higher concentration of DHA in the breast-fed infants (Farquarson et al. 1992).

The evidence that specific fatty acids play a major role in neurodevelopment and cognitive function was first described about 20 years ago. Lamptey \& Walker (1976, $1978 a, b)$, in a series of studies on learning behaviour in rats, demonstrated that essential fatty acid deficiency, particularly $\alpha$-linolenic acid, impaired learning ahilities and from these and other studies the hypothesis that there is a close correlation between brain lipid composition and learning behaviour has evolved. These earlier studics precipitated the supplementation of linoleic and $\alpha$-linolenic acid in artificial formulas. the assumption at that time being that the longer-chain LCP would be synthesized in vilu.

The results of recent clinical studies of visual and cortical function strongly support the laboratory evidence which has undermined this assumption (Carlson 't al. 1990; Uauy et al. 1992). Preterm formula-fed infants have been shown to have a measurable reduction in neuronal function of the visual pathway compared with preterm breast-fed infants, as measured by electroretinogram (Uauy et al. 1992), visual evoked potentials (VEP) and behavioural measures of visual acuity (Birch et al. 1992). These physiological variables correlated with the DHA status of these infants and were corrected by the addition of fish oil, which contains DHA, to the infant formula. Makrides et al. (1993) reported a correlation between visual-evoked potential acuity of healthy term infants and 
Table 3. Correlations between mean infant-dependent measures and child test scores (Modified from Rose et al. 1986)

\begin{tabular}{|c|c|c|c|c|}
\hline \multirow[b]{3}{*}{ Infant measure } & \multicolumn{4}{|c|}{ Child score } \\
\hline & \multicolumn{3}{|c|}{ WPPSI } & \multirow{2}{*}{$\begin{array}{c}\text { British ability } \\
\text { scales }\end{array}$} \\
\hline & Full & Verbal & Performance & \\
\hline Total fixation time & $-0.450 *$ & $-0.596^{* * *}$ & $-0 \cdot 141$ & $-0.588 * *$ \\
\hline Duration of first fixation & $-0.729 \uparrow$ & $-0.778 \ddagger$ & $-0.479 *$ & $-0.852 \div$ \\
\hline Average fixation duration & $-0.644 \dagger$ & $-0.679 \dagger$ & -0.438 & $-0 \cdot 766+$ \\
\hline Average trial duration & $-0.464 *$ & $-0.567 * *$ & $-0 \cdot 198$ & $-0 \cdot 580^{* *}$ \\
\hline
\end{tabular}

WPPSI, Wechsler preschool and primary scales of intelligence.

df 13 .

${ }^{*} P<0 \cdot 05, * * P<0 \cdot 025, * * * P<0 \cdot 01, \dagger P<0 \cdot 005, \ddagger P<0 \cdot 0005$

the level of erythrocyte DHA, suggesting that term infants may be equally susceptible to altered visual development as demonstrated in preterm infants. The longer term effects of these changes are as yet unknown.

Studies on the effect of LCP and cortical function are few. Carlson et al. (1990) studying very-low-birth-weight infants (750-1350 g) studied the effect of supplementation with eicosapentaenoaic acid (EPA) and DHA on growth and development and found that using the Fagan Infantest the percentage of time the control infants spent looking at the novel stimulus at 79 weeks was highly correlated with plasma arachidonic acid.

In assessing cortical function in infants it is vital that the most appropriate tests are applied. Standard tests of infant development such as the Bayley and Griffiths scales (Bayley, 1933), when applied during the first 2 years of life, showed virtually no correlation with intelligence when the same children were tested several years later (McCall, 1979). Recently, psychologists have turned to other measures of infant ability and developed tests which better predict later intelligence. Infant habituation, which is described as a decrease in the attention a baby pays to a stimulus over repeated presentations, has become one of the basic tools for studying perception, memory and learning in infancy. The rationale behind habituation is simple. Infants pay most attention to stimuli and events that are novel, but after several repetitions attention declines, as the infant has learned about the stimulus and recognizes it as familiar. To check that the loss of attention is not due to some other cause such as a change in emotional state, a novelty preference test is performed when the infant is habituated. This is done by showing two stimuli: one that is now familiar and one that is novel. If the novel one receives more attention then the infant has habituated and learned something about the familiar stimulus instead of losing interest in the whole procedure or becoming drowsy. Measures of habituation reflect the infant's capacity for processing and learning information. Even newborn infants can habituate but they are slower than infants just a few months older, and habituation becomes quicker in more mature babies. Habituation, therefore, offers a method for studying abilities such as learning, attention and memory. There are several studies now demonstrating significant correlations between infant habituation and intelligence in later childhood; the children who habituate more rapidly having higher IQ scores (Rose et al. 1986; Table 3). Recent research at Dundee 
University has identified a second infant predictor of childhood intelligence which does suggest that control of attention while solving problems is a key factor. The problemsolving tests can be performed between 6 and 10 months and, depending on the age of the infant, can be either two-step or three-step tasks. For example, a task where the infant has to retrieve a covered object by pulling a cloth to retrieve the cover and then search under the cover to find a toy, can normally be solved by infants at about the age of 9 months. Analysis of video recording of the infants undertaking these tasks allows the task to be scored. When the children were seen again at the age of 3 years and given tests of vocabulary and intelligence there were highly significant positive correlations between the infant problem-solving scores and vocabulary and IQ scores. These new infant assessments offer more sensitive methods with which to explore factors such as LCP which may influence early cognitive development, and are currently being employed in a randomized controlled study of LCP and cortical function during the first year of life.

\section{CONCLUSION}

Breast-feeding during the first 13 weeks of life confers protection against gastrointestinal illness that persists beyond the period of breast-feeding itself. There is also a smaller reduction in respiratory disease. Breast-feeding does not protect the infant against colic, napkin dermatitis or ear infections.

A general statement that breast-feeding protects against allergic disease cannot be made, but a protective effect is most likely if there is a strong family history of allergic disease, and in those infants breast-feeding should be encouraged (possibly in combination with a maternal elimination diet) and the introduction of solids delayed until $4-6$ months.

There is increasing clinical evidence that LCP present in breast milk play a vital role in the development of visual function of newborn infants. There are preliminary clinical data suggesting that LCP may contribute to cortical function and intellectual development but further studies are required.

\section{REFERENCES}

Bauchner, H., Leventhal, J. M. \& Shapiro, E. D. (1986). Studies of breast feeding and infections. How good is the evidence? Journal of the American Medical Association 256, 887-892.

Bayley, N. (1933). Mental growth during the first three years: A developmental study of 61 children by repeated tests. Genetic Psychology Monographs 14, 1-92.

Birch, E., Birch, D., Hoffman, D., Hale, L., Everett, M. \& Uauy, R. (1992). Breast feeding and optimal visual development. Journal of Pediatric Ophthalmology and Strabismus 30, 33-38.

Bouchard, T. J., Lykken, D. T., McGue, M., Segal, N. L. \& Tellegen, A. (1990). Sources of human psychological differences: the Minnesota study of twins reared apart. Science 250, 223-228.

Carlson, S. E., Rhodes, P. G. \& Ferguson, M. G. (1985). DHA status of preterm infants at birth and following feeding with human milk or formula. American Journal of Clinical Nutrition 44, 798-804.

Carlson, S. E.. Rhodes, P. G., Rao, V. S. \& Goldgar, D. E. (1987). Effect of fish oil supplementation on the n-3 fatty acid content of red blood cell membranes in preterm infants. Pediatric Research 21, 507-510.

Carlson, S. E., Werkman, S. H., Peeples, J. M., Cooke, R. J. \& Wilson, W. M. (1992). Plasma phospholipid arachidonic acid and growth and development of preterm infants. Symposium; Recent Advances in Infant Feeding, pp. 22--27 [B. Koletzko, A. Okken, J. Rey, B. Salle and J. P. Van Biervliet, editors]. Stuttgart: Georg Thieme Verlag.

Chiba, Y., Minagawa, T., Mito, K., Nakane, K., Suga, T., Honjo, T. \& Nako, T. (1987). Effect of breast feeding on responses of systemic interferon and virus-specific lymphocyte transformation in infants with respiratory syncytial virus infection. Journal of Medical Virology 21, 7-14. 
Clark, K. J., Makrides, M., Neumann, M. A. \& Gibson, R. A. (1992). Determination of the optimal ratio of linoleic and alpha-linolenic acid in infant formulas. Journal of Pediatrics 120, S151-S158.

Crawford, M. A. \& Sinclair, A. J. (1971). Nutritional influences in the evolution of mammalian brain. In Lipids, Malnutrition and the Developing Brain. Ciba Foundation Symposium, pp. 267-292 [K. Elliot and J. Knight, editors]. Amsterdam: Elsevier.

Cunningham, A. S., Jelliffe, D. B. \& Jelliffe, E. F. P. (1991). Breast feeding and health in the 1980's: A global epidemiologic review. Journal of Pediatrics 118, 659-666.

Duchen, K. \& Bjorksten, B. (1991). Sensitisation via the breast milk. Advances in Experimental Medicine and Biology 310, 427-436.

Ehrlich, P. (1892). Ueber Immunitaet durch Vererbung und Saeugung (About inherited immunity and immunity through suckling). Zeitschrift für Hygiene und Infektionskrankheiten 12, 183-203.

Farquarson, J., Cockburn, F., Patrick, W. A., Jamieson, E. C. \& Logan, R. W. (1992). Infant cerebral cortex phospholipid fatty-acid composition and diet. Lancet 340, 810-813.

Fergusson, D. M., Horwood, L. J., Beautrais, A. L., Shannon, F. T. \& Taylor, B. (1981). Eczema and infant diet. Clinical Allergy 11, 325-331.

Forsyth, J. S., Ogston, S. A., Clark, A., Florey, C. du V. \& Howie, P. W. (1993). Relationship between early introduction of solid food to infants and their weight and illnesses during the first two years of life. British Medical Journal 306, 1572-1576.

Friss, H. E., Rubin, L. G., Carsons, S., Baranowski, J. \& Lipsitz, P. J. (1988). Plasma fibronectin concentrations in breast fed and formula fed neonates. Archives of Diseases in Childhood 63, 528-532.

Goldman, A. S., Rudloff, H. E. \& Schmalstieg, F. C. (1991). Are cytokines in human milk? Advances in Experimental Medicine and Biology 310, 93-97.

Grulee, C. G. \& Sanford, H. N. (1936). The influence of breast and artificial feeding on infantile eczema. Journal of Pediatrics 9, 223-225.

Hanson, L. A. (1961). Comparative immunological studies of the immune globulins of human milk and of blood serum. International Archives of Allergy and Applied Immunology 18, 241-267.

Hanson, L. A. \& Brandtzaeg, P. (1988). The mucosal defense system. In Immunological Diseases in Infants and Children, 3rd ed., pp. 222-241 [R. T. Stiehm, editor]. Philadelphia: W. B. Saunders.

Hanson, L. A., Carlsson, B., Cruz, J. R., Garcia, B., Holmgren, J., Khan, S. R. \& Lindblad, B. S. (1979). Immune response to the mammary gland. In Immunology of Breast Milk, pp. 145-157 [P. L. Ogra and D. Dayton, editors]. New York: Raven Press.

Hernell, O. \& Blackberg, L. (1988). Antiparasitic factors in human milk. In Biology of Human Milk. Nestlé Nutrition Workshop Series, vol. 15 [L. A. Hanson, editor]. Vevey: Nestec Ltd, New York: Raven Press.

Hoefer, A. \& Hardy, M. C. (1929). Later development of breast fed and artificially fed infants. Journal of the American Medical Association 92, 615-619.

Howie, P. W., Forsyth, J. S., Ogston, S. A., Clark, A. \& Florey, C. du V. (1990). Protective effect of breast feeding against infection. British Medical Journal 300, 11-16.

Koldovsky, O., Bedrick, A., Pollack, P., Rao, R. K. \& Thornburg, W. (1988). The possible role of hormones and hormone-related substances in milk. In Biology of Human Milk, pp. 123-139 [L. A. Hanson, editor]. New York: Raven Press.

Kramer, M. S. (1988). Does breast feeding help protect against atopic disease? Biology, methodology, and a golden jubilee of controversy. Journal of Pediatrics 112, 181-190.

Lamptey, M. S. \& Walker, B. L. (1976). A possible essential role for dietary linolenic acid in the development of the young rat. Journal of Nutrition 106, 86-93.

Lamptey, M. S. \& Walker, B. L. (1978a). Physical and neurological development of the progeny of female rats fed an essential fatty acid-deficient diet during pregnancy/or lactation. Journal of Nutrition 108, 351-357.

Lamptey, M. S. \& Walker, B. L. (1978b). Learning behaviour and brain lipid composition in rats subjected to essential fatty acid deficiency during gestation, lactation, and growth. Joumal of Nutrition 108, 358-367.

Lucas, A., Morley, R., Cole, T. J., Lister, G. \& Leeson-Payne, C. (1992). Breast milk and subsequent intelligence quotient in children born preterm. Lancet 339, 261-264.

McCall, R. B. (1979). The development of intellectual functioning in infancy and the prediction of later IQ. In Handbook of Infant Development, pp. 707-741 [J. D. Osofsky, editor]. Chichester: Wiley.

McClelland, D. B. L., McGrath, J. \& Samson, R. R. (1978). Antimicrobial factors in human milk. Studies of concentration and transfer to the infant during the early stages of lactation. Acta Paediatrica Scandinavica 271, Suppl., 1-20.

Makrides, M., Simmer, K., Goggin, M. \& Gibson, R. A. (1993). Erythrocyte docosahexaenoic acid correlates with the visual response of healthy, term infants. Pediatric Research 34, 425-427. 
Martinez, M. (1992). Tissue levels of polyunsaturated fatty acids during early human development. Journal of Pediatrics 120, S129-S138.

Miller, D. L., Hirvonen, T. \& Gitlin, D. (1973). Synthesis of IgE by the human conceptus. Journal of Allergy and Clinical Immunology 52, 182-188.

Pollock, J. I. (1989). Mother's choice to provide breast milk and development outcome. Archives of Disease in Childhood 64, 763-764.

Reddy, V., Bhaskaram, C., Raghuramulu, N. \& Jagadeesan, V. (1977). Antimicrobial factors in human milk. Acta Paediatrica Scandinavica 66, 229-232.

Rodgers, B. (1978). Feeding in infancy and later ability and attainment: a longitudinal study. Developmental Medicine and Child Neurology 20, 421-426.

Rose, D. H., Slater, A. \& Perry, H. (1986). Prediction of childhood intelligence from habituation in early infancy. Intelligence 10, 251-263.

Stephens, S., Dolby, J. M., Montreuil, J. \& Spik, G. (1980). Differences in inhibition of the growth of commensal and enteropathogenic strains of Escherichia coli by lactotransferrin and secretory immunoglobulin A isolated from human milk. Immunology 41, 597-603.

Taylor, B. (1977). Breast versus bottle feeding. New Zealand Medical Journal 85, 235-238.

Uauy, R., Birch, E., Birch, D. \& Peirano, P. (1992). Visual and brain function measurements in studies of n-3 fatty acid requirements of infants. Journal of Pediatrics 120, S168-S180.

Walker, W. A. \& Isselbacher, K. J. (1977). Intestinal antibodies. New England Journal of Medicine 297, $767-773$.

Wright, P. \& Deary, I. J. (1992). Breastfeeding and intelligence. Lancet 339, 612. 